\title{
Torilis japonica extract fraction compound, EGFR-targeted inhibition of cancer abnormal metastasis in A549 lung cancer cells
}

\author{
GUEN TAE KIM $^{1}$, SANG-YONG KIM ${ }^{2}$ and YOUNG MIN KIM ${ }^{1}$ \\ ${ }^{1}$ Department of Biological Sciences, College of Life Science and Nanotechnology, \\ Hannam University, Yuseong-gu, Daejeon; ${ }^{2}$ Department of Food Science and \\ Biotechnology, Shinansan University, Ansan-city, Gyeonggi-do, Republic of Korea
}

Received January 20, 2017; Accepted June 14, 2017

DOI: $10.3892 /$ or.2017.5771

\begin{abstract}
The number of patients who die from lung cancer is steadily increasing. According to the 2012 statistics, lung cancer accounts for the highest percentage of death from cancer in both sexes. Many research studies found that lung cancer can be caused not only by smoking but by outdoor pollution, and it leads to over-activation of various surface proteins in cancer cells. The over-activity of epidermal growth factor receptor (EGFR) is implicated as a crucial factor in inducing abnormal metastasis of lung cancer cells. In this study, we investigated the inhibitory effect of Torilis japonica extract (TJE) major fraction compound in A549 lung cancer cells by inhibiting EGFR activity. We confirmed that inhibitory effect of TJE on the abnormal metastasis using invasion assay and 3D cell culture method, as well as the inhibition of EGFR signaling pathway, co-binding with Stat 3 and dimer formation for translocation to the nucleus. We confirmed the EGFR targets inhibition of TJE when compared with EGFR knockdown group using siRNA transfection. The CAM assay confirmed once again the efficacy of the TJE. We suggest that TJE is a new potential reagent for EGFR-targeted therapy and anti-abnormal metastasis in A549 lung cancer cells.
\end{abstract}

\section{Introduction}

The recorded incidence of cancer is increasing because of the increasing number of aging populations, as well as increasing prevalence of risk factors such as smoking, overweight and changing dietary patterns $(1,2)$. Smoking is the most

Correspondence to: Professor Young Min Kim, Department of Biological Sciences, College of Life Science and Nanotechnology, Hannam University, Yuseong-dero 1646, Yuseong-gu, Daejeon 34054, Republic of Korea

E-mail: kym@hnu.kr

Key words: Torilis japonica, EGFR, abnormal metastasis, nucleus translocation, CAM assay common reason for cancer incidence and deaths. In 2012, lung cancer patients due to smoking and other causes were the leading cause of cancer death worldwide both in males and females (3). According to this tendency, there is a movement to reduce smoking in the world. However, apart from a decrease in smoking, the number of patients and death rate caused by lung cancer has not decreased. Recent studies have shown that smoking does not simply induce an increase in lung cancer patients. Other known risk factors for lung cancer include exposure to outdoor pollution and this is the largest cause of lung cancer patients in China and East Asia (4-6).

Many of the factors involved in outdoor pollution induce cancerization through gene mutation, as well as induction of overgrowth and abnormal-metastasis of cancer cells leading to over-activity of surface proteins such as the growth factor receptors $(7,8)$. Over-activation of epidermal growth factor receptor (EGFR) leads to not only abnormal proliferation by inducing Erk and Akt activation, which is a common cancer factor but increases abnormal metastasis of cancer cells through the JAK-STAT signaling pathways (9-11). The active EGFR directly translocates into the cancer cell nucleus and induces expression of factors involved in cancer cells metastasis. Recent studies have shown that EGFR-activated Stat3 induces expression of the SNAIL family and induces abnormal metastasis of cancer cells $(12,13)$. Moreover, the EGFR co-binding with Stat 3 and EGFR dimers translocate into the cancer cell nucleus and it leads to expression of factors related to cancer cell proliferation and invasion (14-16). Therefore, to inhibit abnormal growth and metastasis of cancer cells, it is very important to find a target substance capable of inhibiting the EGFR activation. Recently, we discovered a novel substance that can inhibit the abnormal metastasis of MCF-7 breast cancer cells by targeting EGFR (17).

We found that Torilis japonica extract (TJE) major fraction substance not only inhibits the activity of EGFR but regulate the expression of factors involved in cancer cell abnormal metastasis. However, we found that the substance targeted EGFR, but could not confirm that exact mechanism. In this study, we investigated the mechanism by which TJE targets EGFR and inhibit the abnormal metastasis in A549 lung cancer cells. In addition to the inhibition of surface of EGFR, 
we also examined the mechanism of expression suppression of abnormal metastasis-related factors through translocation to the cancer cell nucleus.

\section{Materials and methods}

Plant material and preparation of TJE. Dried whole fruit of TJE was purchased from Na-num Pharmacy (Kyung-buk, Korea). Plant material (200 g) was extracted two times with $95 \%$ ethanol $(800 \mathrm{ml})$ at room temperature for 3 days and it was subsequently filtered (raw compound). For the active compound fraction, raw compound was mixed with compound:Methanol (9:1), and $200 \mu \mathrm{l}$ aliquots were injected into a series 1100 HPLC system (Agilent Technologies, Inc., Santa Clara, CA, USA). A symmetry C-18 column (4.6x $2.5 \mathrm{~cm}$; Waters, Milford, MA, USA) was used. The mobile phase consisted of acetonitrile:water solution (3:1, v/v) pumped at a rate of $1 \mathrm{ml} / \mathrm{min}$. Major peaks was recorded and same fractions were combined. The combined filtrate was concentrated under vacuum at $60^{\circ} \mathrm{C}$, and completely dried by freeze drying. TJE powder was dissolved in DMSO and filtrated by $0.2-\mu \mathrm{m}$ pore size filter for in vitro and ex vivo studies.

Reagent. Phalloidin, EGF were from Sigma-Aldrich (St. Louis, MO, USA). Specific antibodies that recognized p-EGFR, p-Stat3, Stat3, p-JAK2, JAK2, p-Akt, p-Erk, Akt, Erk, $\beta$-actin were obtained from Cell Signaling Technology (Beverly, MA, USA) and EGFR, E-cadherin, N-cadherin from Santa Cruz Biotechnology (Dallas, TX, USA).

Cell culture. A549 and fibroblast cells were obtained from the American Type Culture Collection (ATCC, Rockville, $\mathrm{MD}$, USA). Cells were grown in DMEM medium (HyClone, Waltham, MA, USA) containing $10 \%$ fetal bovine serum (HyClone) and $1 \%$ antibiotics $(100 \mathrm{mg} / \mathrm{l}$ streptomycin, $100 \mathrm{U} / \mathrm{ml}$ penicillin) at $37^{\circ} \mathrm{C}$ in a $5 \% \mathrm{CO}_{2}$ atmosphere. Cells were suspended by Trypsin-EDTA (HyClone) and separated $1.5 \times 10^{5} / \mathrm{ml}$ at each plate, every $48 \mathrm{~h}$.

Invasion assay. Quantitative cell invasion assays were performed using a modified Boyden chamber (Costar, Corning Inc., Corning, NY, USA) with $8.0 \mu \mathrm{m}$ pore polycarbonate membrane inserts with Matrigel-coated 24-well plates as described previously. The lower chamber was filled with the complete medium for control and complete medium with TJE at the indicated dose and EGF (see Figures). The A549 cells $\left(5 \times 10^{4}\right.$ cells $\left./ \mathrm{ml}\right)$ in serum-free medium were added into the upper chamber. The cells were allowed to invade for $24 \mathrm{~h}$ at $37^{\circ} \mathrm{C}$. The non-invasive cells were removed from the upper surface of the membrane by scraping with a cotton swab, and the invasive cells were stained with crystal violet and photographed under a bright field microscope (Carl Zeiss, Thomwood, NY, USA).

Immunofluorescence staining with wound healing assay. Cells were seeded $2.5 \times 10^{6} / \mathrm{ml}$ in 12 -well plate with the cover glass, and incubated to $100 \%$ confluence. After the incubation, the wound in the cell monolayer in the center of the well was treated with TJE. After treatment, at the indicated time and dose at $37^{\circ} \mathrm{C}$ in a $5 \% \mathrm{CO}_{2}$ atmosphere, the cells were fixed with
$3.7 \%$ formaldehyde for $20 \mathrm{~min}$ and permeabilized with $0.2 \%$ Triton X-100 for $20 \mathrm{~min}$ for stress fiber staining. For staining of specific proteins, cells were fixed and permeabilized with $95 \%$ methyl alcohol for 15 min. Cells were washed with PBS twice and reacted with specific antibody overnight at $4^{\circ} \mathrm{C}$. Cells were washed with PBS twice and reacted to secondary antibody and stained with $0.1 \%$ Phalloidin-FITC for $40 \mathrm{~min}$. Fluorescence was detected by confocal microscopy (Carl Zeiss).

$3 D$ cell culture (organotypic cell culture) for invasive cell detection. Human fibroblast cells were seeded on $0.3-\mu \mathrm{m}$ pore size cell culture insert plate and incubation with Matrigel and type I collagen mixture. After cell mixture was detached from the insert plate, $2 \times 10^{5} / \mathrm{ml}$ A549 cancer cells were placed in the mixture and incubated for 1 week in the complete medium. After incubation, the 3D cell formation medium was placed in the bottom well and cultured for 3 weeks while changing the medium every 2 days. The appropriate amount of TJE and EGF was added to the new medium, and place in the bottom well, and incubate for 1 week. Metastatic cancer cells were identified using hematoxylin and eosin (H\&E) staining.

Egg preparation and cancer cell inoculation. Fertilized chicken eggs were purchased from a local hatchery and incubated for 8 days after breeding at $37^{\circ} \mathrm{C}$ with $45 \%$ humidity. Eggs were cleaned with pre-warmed $70 \%$ ethanol and a small hole was drilled into the eggshell where the air sac is located. A 2-cm window was carefully opened for inoculation. The hole was then vacuumed to exclude air, thus creating space for the CAM. A total of $1 \times 10^{6}$ cells re-suspended in $20 \mu \mathrm{l}$ serum and antibiotics-free DMEM medium with Matrigel was added on the CAM. The window was then covered with medical film and the egg was placed back into the incubator. After fiveday inoculation, silicon ring was implanted on micro-tumor tissue and TJE treated with or without EGF. Seven more days after incubation, micro-tumors were removed from CAMs, for metastasis study, specific tissue of developing chickens was harvested and stored at $-80^{\circ} \mathrm{C}$ before DNA extraction.

Subcellular protein fraction. A subcellular protein fraction kit was used (Thermo Fisher Scientific, Waltham, MA, USA). Cells were seeded at $1 \times 10^{6} / \mathrm{ml}$ in $100-\mathrm{mm}$ dish and incubated for $24 \mathrm{~h}$. After the incubation, treated with the test compound for the indicated times (see Figures) at $37^{\circ} \mathrm{C}$ in a $5 \% \mathrm{CO}_{2}$ atmosphere. After the incubation, subcellular proteins were separated according to the manufacturer's instructions. A separate protein was analyzed by western blotting.

Immunoprecipitation. We used sure-bead protein $\mathrm{G}$ magnetic beads kit (Bio-Rad, Hercules, CA, USA). Cells were seeded at $1 \times 10^{6} / \mathrm{ml}$ in $100-\mathrm{mm}$ plate and incubated for $24 \mathrm{~h}$. After incubation, cells were treated with the test compound for $24 \mathrm{~h}$ at $37^{\circ} \mathrm{C}$ in a $5 \% \mathrm{CO}_{2}$ atmosphere. Whole lysate and nucleus fraction proteins were incubated with specific antibody bound magnetic beads. Beads were washed using a magnetizer and PBS. Target proteins were eluted in 1X non-reducing sample buffer and analyzed by western blotting.

Protein dimerization. We used a BS3 (Thermo Fisher Scientific) protein crosslinker. Cells were seeded at $1 \times 10^{6} / \mathrm{ml}$ 


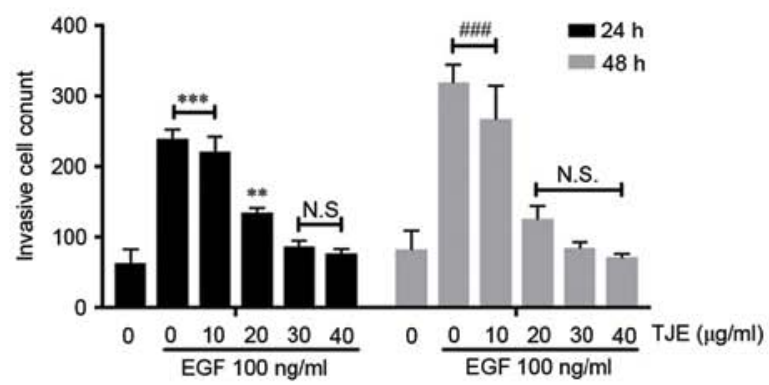

C

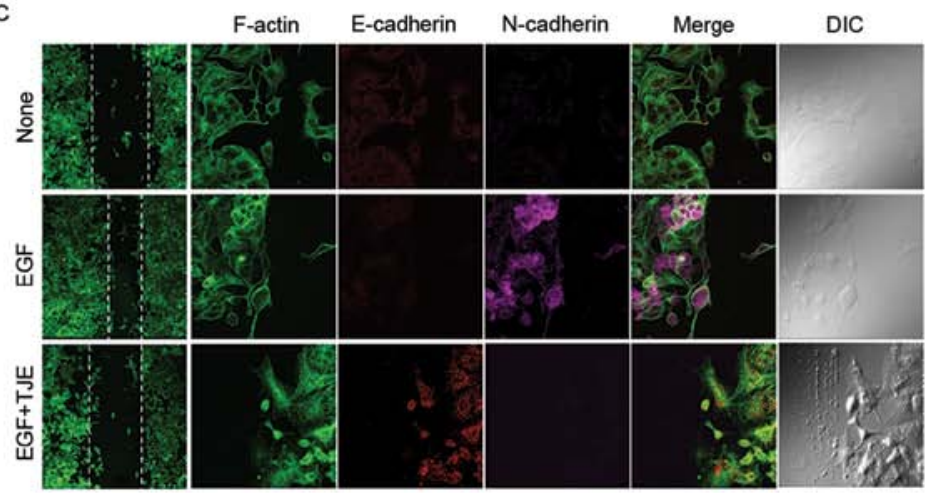

B

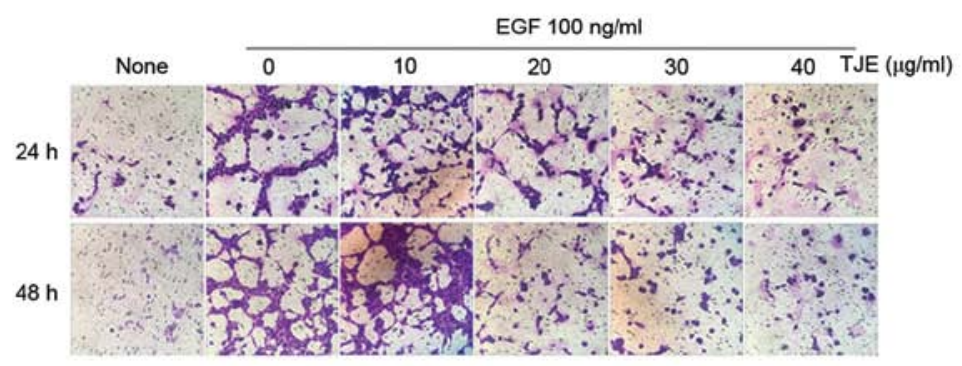

D

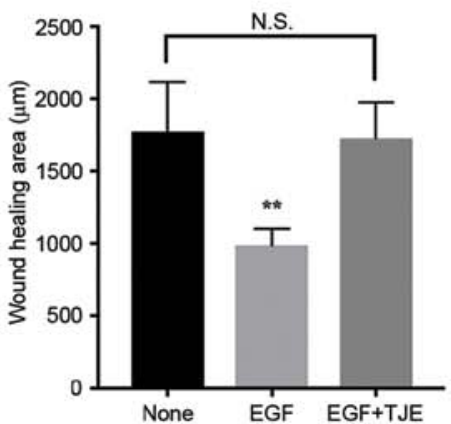

E

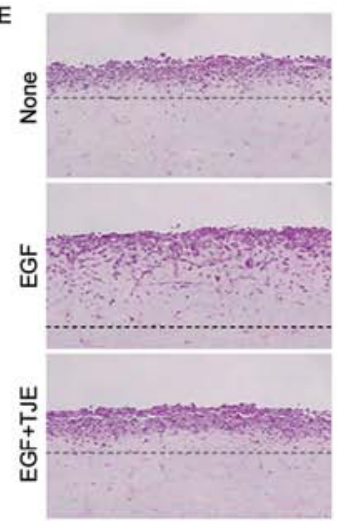

Figure 1. TJE suppresses cell migration and invasion in EGF-stimulated A549 cells. (A and B) Invasive cells were measured by invasion assay. Invasive cells were determined by counting cells in microscopic fields per sample. Compared to control; ${ }^{* *} \mathrm{P}<0.01,{ }^{* * *} \mathrm{P}<0.001$ in $24 \mathrm{~h}$ and compared to control in $48 \mathrm{~h}$; ${ }^{\# \# \# P} \mathrm{P}<0.001$ (each experiment's $\mathrm{n}=3$ ). N.S., not significant. (C and D) Anti-migration abilities were detected by wound healing assay with immunofluorescence staining. F-actin (green), E-cadherin (red), N-cadherin (violet). For the counter staining, we using a DIC image. The wound healing area was quantified using Prism after confirming the degree of reduction by using imageJ. Compared to control; ${ }^{* *} \mathrm{P}<0.01$ (each experiment $\mathrm{n}=3$ ). N.S., not significant. (E) Invasive cancer cells were qualitatively identified using $3 \mathrm{D}$ cell culture.

in $100-\mathrm{mm}$ dish and incubated for $24 \mathrm{~h}$. After the incubation, treated with the test compound for the indicated times at $37^{\circ} \mathrm{C}$ in a $5 \% \mathrm{CO}_{2}$ atmosphere. After the incubation, proteins were extracted with non-denaturing lysis buffer, and reacted with BS3 according to manufacturer's instructions. Protein dimerization was analyzed by western blotting.

Transient transfection with small interfering RNA. Small interfering RNA (siRNA) was purchased by Dharmacon (Chicago, IL, USA), and a Nucleofector (Lonza, Basel, Switzerland) for transfection. For transient transfection, $2 \times 10^{6} / \mathrm{ml}$ cells were re-suspended in a transfection reagent with targeting siRNA. The siRNA was inserted by electric shock according to the manual provided by the manufacturer. After incubation for $24 \mathrm{~h}$, cells were treated with the compound.

Western blotting. Cells were seeded at $1 \times 10^{5} / \mathrm{ml}$ in 6-well plate and incubated for $24 \mathrm{~h}$, and after the incubation, treated with the test compound for indicating times at $37^{\circ} \mathrm{C}$ in a $5 \% \mathrm{CO}_{2}$ atmosphere. Cells were rinsed twice with ice-cold PBS and scraped with lysis buffer $(50 \mathrm{mM}$ Tris- $\mathrm{HCl} \mathrm{pH} 8.0,150 \mathrm{mM}$ $\mathrm{NaCl}, 1 \% \mathrm{NP} 40,0.5 \%$ sodium deoxycholate, $1 \mathrm{mM}$ PMSF) and subjected to the western blot analysis. The 1st antibody reaction was overnight at $4^{\circ} \mathrm{C}$ and 2 nd antibody for $75 \mathrm{~min}$ at room temperature with slow agitation.

Quantitative polymerase chain reaction (PCR). Total RNA was extracted using RiboEx (GeneAll Biotechnology, Seoul,
Korea) according to the manufacturer's instructions, and cDNA was generated using ReverseAids cDNA synthesis kit (Thermo Fisher Scientific) according to the manufacturer's instructions. RT-PCR was performed with the following temperature profile: a pre-denaturation step of $10 \mathrm{~min}$ at $95^{\circ} \mathrm{C}$, followed by 35 cycles of $95^{\circ} \mathrm{C}$ for $30 \mathrm{sec}$, annealing temperature for $30 \mathrm{sec}$ and $72^{\circ} \mathrm{C}$ for $30 \mathrm{sec}$ and a final exposure at $72^{\circ} \mathrm{C}$ for $10 \mathrm{~min}$. qPCR was performed using qPCR greenstar master-mix (Bioneer, Seoul, Korea) and StepOne ${ }^{\mathrm{TM}}$ (Applied Biosystems, Foster city, CA, USA) for amplification and detection. A pre-denaturation step of $10 \mathrm{~min}$ at $95^{\circ} \mathrm{C}$, followed by 42 cycles of $95^{\circ} \mathrm{C}$ for $20 \mathrm{sec}$, annealing and extension for $60 \mathrm{sec}$. Specific primer sequence for amplification was: forward, TAGATGCCCCCAAATCTCAG; reverse, GAGCT GCTCCATCTGTAGGG.

Statistical analysis. Invasive cells, wound healing area and gene expression were statistically analyzed using ANOVA test (Prism version 7; GraphPad Software, Inc., La Jolla, CA, USA). $\mathrm{P}<0.05$ was considered to indicate a statistically significant difference.

\section{Results}

TJE suppresses cell migration and invasion in EGF-stimulated A549 cells. To confirm the abnormal metastasis inhibition effect of TJE, the number of invasion cancer cells was counted after TJE treatment in EGF-stimulated A549 lung cancer cells. The concentration was increased, the number of metastatic cancer 


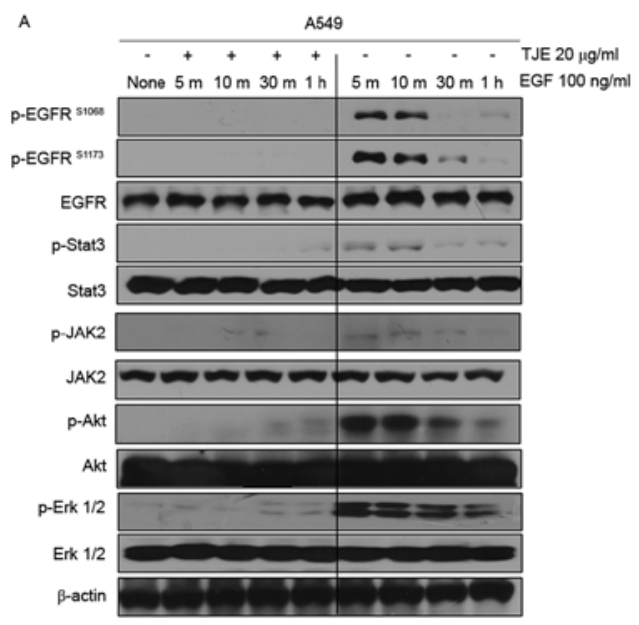

B

c
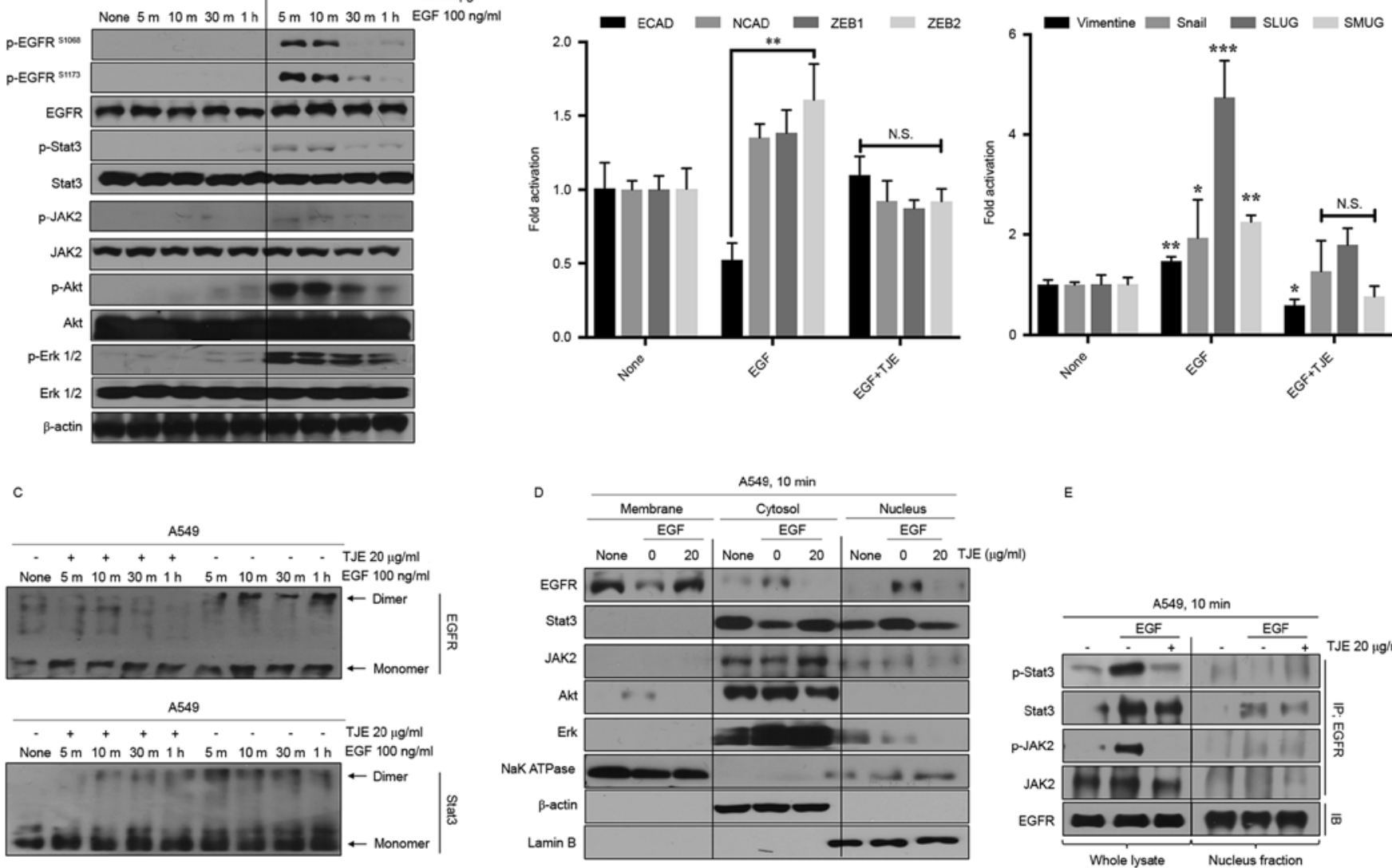

E

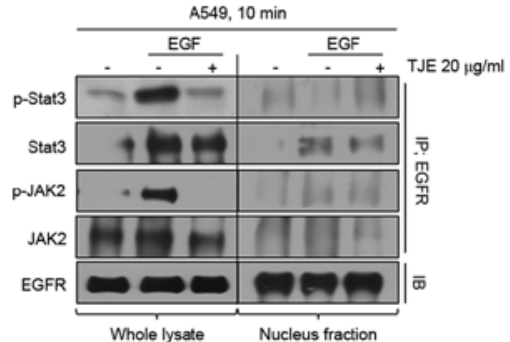

Figure 2. TJE regulates expression of EMT marker and activation of EGFR downstream signaling pathways. (A) The change of EGFR phosphorylation level was examined and its downstream protein phosphorylation levels were detected by western blotting. (B) EMT marker gene expression levels were examined by qPCR. Compared to control; ${ }^{*} \mathrm{P}<0.05,{ }^{* *} \mathrm{P}<0.01,{ }^{* * *} \mathrm{P}<0.001$ in $24 \mathrm{~h}$ (each experiment's $\mathrm{n}=3$ ). N.S., not significant. (C) The dimerization of EGFR and Stat 3 was confirmed by western blotting after the reaction with Bs3. (D and E) The nucleus translocation of EGFR and JAK2-stat3 was confirmed by western blotting after protein fractionation to membrane-cytosol-nucleus. Co-binding of EGFR with JAK2-Stat3 was confirmed by western blotting via co-IP.

cells was reduced (Fig. 1A and B). Moreover, it was confirmed through 3D cell culture method that the extent of cancer cells that were transferred to the normal cell layer was reduced by the TJE treatment (Fig. 1E). Immunofluorescence analysis of E-cadherin, N-cadherin and F-actin with or without TJE treatment in EGF-stimulation. Despite the EGF-stimulation, TJE not only upregulated expression of E-cadherin but reduced $\mathrm{N}$-cadherin expression. Moreover, EGF-induced cell migration activities, but there was a decrease in the migration area in TJE co-treated group (Fig. 1C and D).

TJE regulates expression of EMT marker and activation of EGFR downstream signaling pathways. To confirm the EGFR signaling regulation by TJE, we analyzed the activity of EGFR and its downstream signaling proteins such as Akt, Erk, Stat3 and JAK2 in EGF was treated with time after TJE treatment. Fig. 2A shows that the activity of EGFR and its downstream proteins were decreased by TJE treatment. Moreover, the expression of specific factors related to cancer cell metastasis such as SNAIL family, $\mathrm{N}$-cadherin and vimentin was reduced while the expression of E-cadherin was found to be normal in TJE treatment group (Fig. 2B). In the case of EGFR and Stat3, which form a dimer in EGF-stimulation, dimer formation was inhibited in TJE treatment group (Fig. 2C). We confirm that TJE inhibited the translocation to the nucleus of
EGFR and Stat3, and the co-binding of EGFR with Stat3 was also decreased (Fig. 2D and E).

TJE suppresses abnormal metastasis through the EGFR target pathways. As a result of comparing the inhibitory effect of the TJE against cancer cell abnormal metastasis in the state where a specific protein is knocked down using a siRNA transfection, the inhibition of invasive cells, metastasis-related gene expression and the change of wound healing area in TJE treatment group were not different compared with EGFR knockdown group. There was no difference in the JAK2 knockdown group. However, in the Stat 3 knockdown group, the change was similar to that of the EGF only treatment group (Fig. 3B-D). In addition, the formation of stress fibers, which indicate the movement of cancer cells, was not significantly different from that of the EGFR knockdown group in the TJE treated group (Fig. 3A).

TJE inhibits cancer abnormal metastasis in CAM. To confirm the suppressed abnormal metastasis activity by TJE in an ex vivo model, we made a cancer cell implantation model in CAM. As shown in Fig. 4, EGF treatment group formed blood vessels in the cellular matrix with cancer cells. However, TJE co-treatment group did not form blood vessel or contract the cellular matrix. From quantification PCR 
A

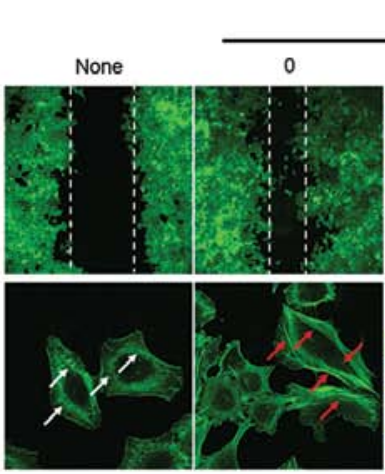

c

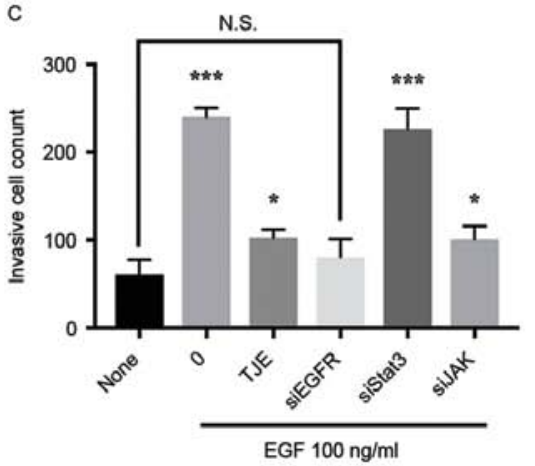

EGF $100 \mathrm{ng} / \mathrm{ml}$

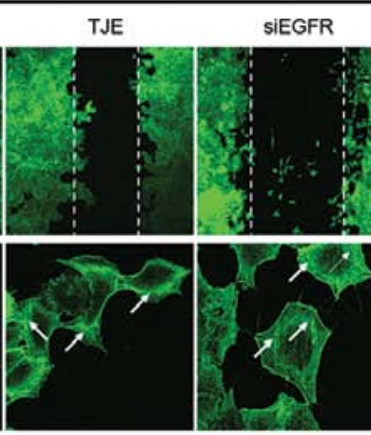

siStat3

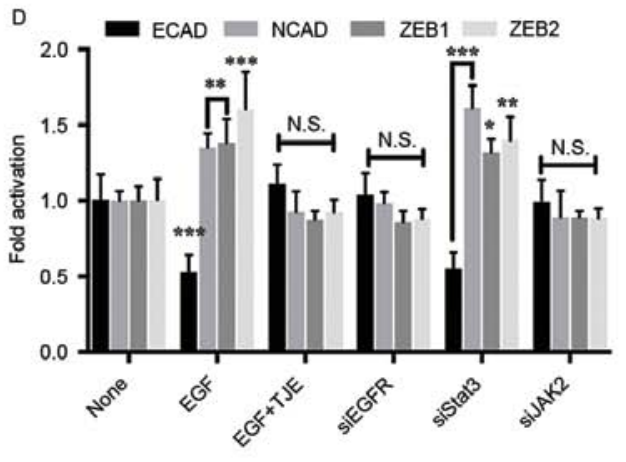

B
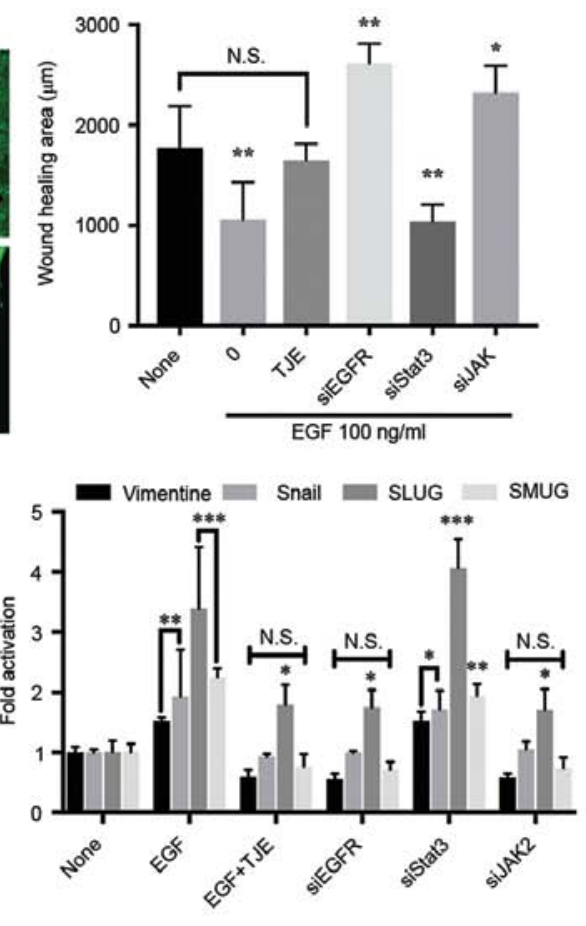

Figure 3. TJE suppresses abnormal metastasis through the EGFR target pathways. The specific protein was knocked down using siRNA and treated with the TJE in EGF-stimulated A549 lung cancer cells. (A and B) Anti-migration abilities were detected by wound healing assay with immunofluorescence staining. F-actin (green) and stress fiber are indicated by red arrows. The wound healing area was quantified using Prism after confirming the degree of reduction by using imageJ. Compared to control; ${ }^{*} \mathrm{P}<0.05$, ${ }^{* * *} \mathrm{P}<0.001$ (each experiment's $\mathrm{n}=3$ ). N.S., not significant. (C) Invasive cells were measured by invasion assay. Invasive cells were determined by counting cells in microscopic fields per sample. Compared to control; ${ }^{*} \mathrm{P}<0.05,{ }^{* *} \mathrm{P}<0.01,{ }^{* * *} \mathrm{P}<0.001$ (each experiment $\mathrm{n}=3$ ). N.S., not significant. (D) EMT marker gene expression levels were examined by qPCR. ${ }^{*} \mathrm{P}<0.05,{ }^{* *} \mathrm{P}<0.01$, ${ }^{* * * *} \mathrm{P}<0.001$ (each experiment $\mathrm{n}=3$ ). N.S., not significant.

Table I. Primer sequences for the amplification of target genes.

\begin{tabular}{|c|c|c|c|}
\hline Gene & Primer sequence $\left(5^{\prime}-3^{\prime}\right)$ & Amplification size (bp) & Annealing temp. $\left({ }^{\circ} \mathrm{C}\right)$ \\
\hline E-cadherin & $\begin{array}{l}\text { F: CGGACGATGATGTGAACACC } \\
\text { R: TTGCTGTTGTGCTTAACCCC }\end{array}$ & 213 & 60.0 \\
\hline N-cadherin & $\begin{array}{l}\text { F: GACAATGCCCCTCAAGTGTT } \\
\text { R: CCATTAAGCCGAGTGATGGT }\end{array}$ & 179 & 59.5 \\
\hline Vimentin & $\begin{array}{l}\text { F: GAGAACTTTGCCGTTGAAG } \\
\text { R: TCCAGCAGCTTCCTGTAGGT }\end{array}$ & 170 & 59.5 \\
\hline SNAIL & $\begin{array}{l}\text { F: CCCCAATCGGAAGCCTAACT } \\
\text { R: ACAGAGTCCCAGATGAGCA }\end{array}$ & 157 & 60.0 \\
\hline SLUG & $\begin{array}{l}\text { F: CTTTTTCTTGCCCTCACTGC } \\
\text { R: GCTTCGGAGTGAAGAAATGC }\end{array}$ & 224 & 59.0 \\
\hline SMUG & $\begin{array}{l}\text { F: GTCCGCAGTCTTACGAGGAG } \\
\text { R: CCAGCTTGAGGGTCTGAATC }\end{array}$ & 159 & 60.0 \\
\hline ZEB1 & $\begin{array}{l}\text { F: TGGACTGAGTGTGGAAAAGC } \\
\text { R: TGGTGATGCTGAAAGAGACG }\end{array}$ & 237 & 60.0 \\
\hline ZEB2 & $\begin{array}{l}\text { F: TTCCTGGGCTACGACCATAC } \\
\text { R: GCCTTGAGTGCTCGATAAGG }\end{array}$ & 393 & 60.0 \\
\hline GAPDH & $\begin{array}{l}\text { F: CAAGGTCATCCATGACAACTTTG } \\
\text { R: GTCCACCACCCTGTTGCTGTAG }\end{array}$ & 496 & 58.0 \\
\hline
\end{tabular}

F, forward, R, reverse. 
A

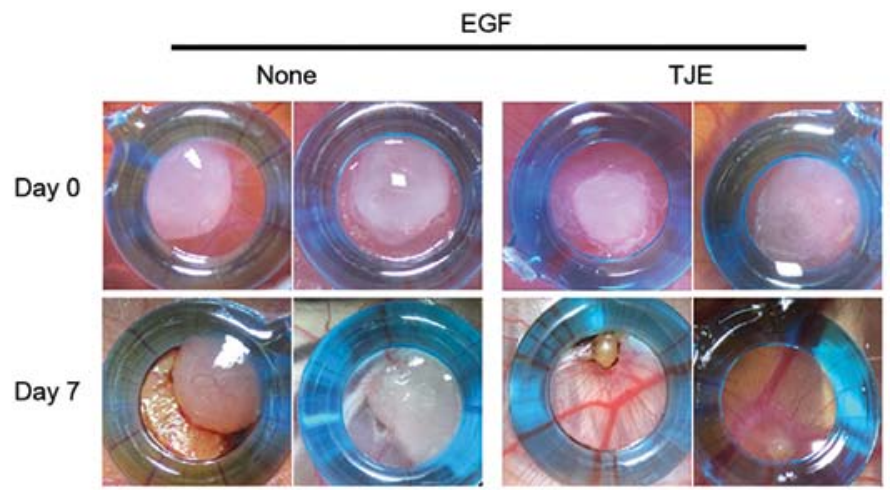

B
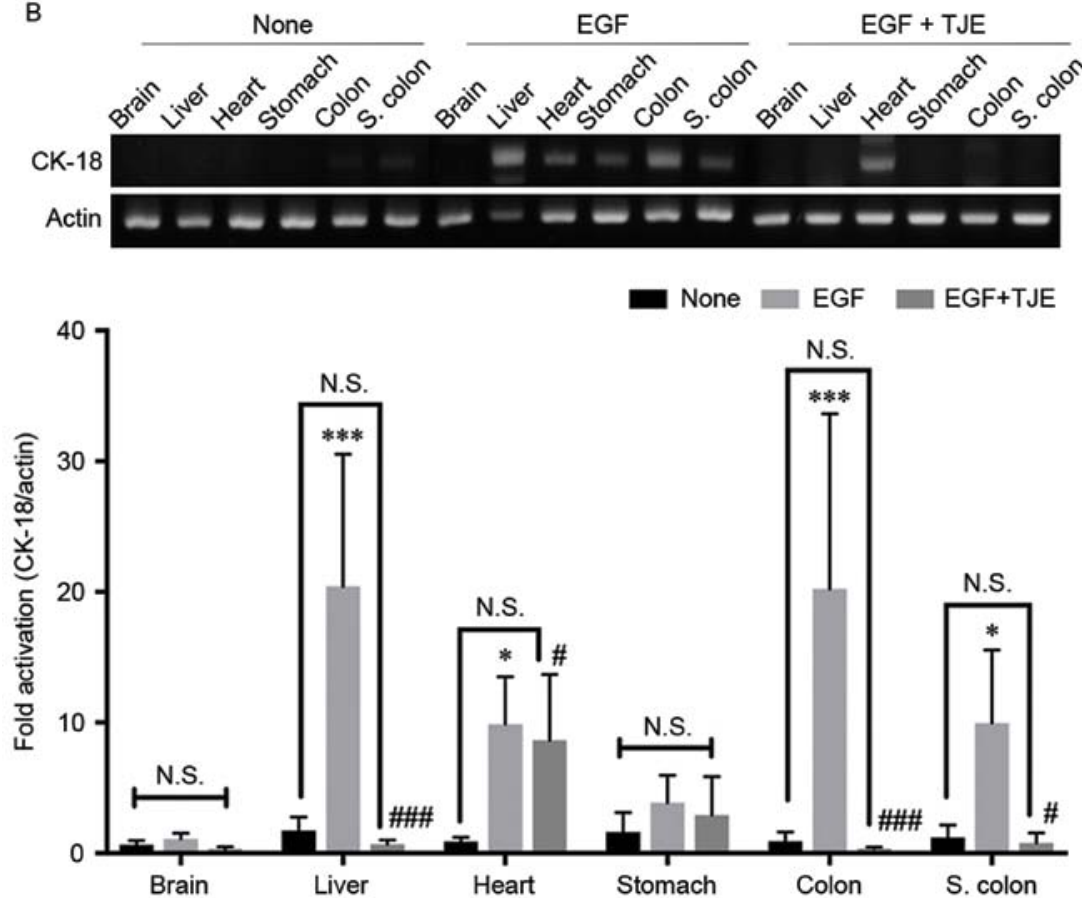

Figure 4. TJE inhibits cancer abnormal metastasis in CAM. (A) After the cancer cells had been placed on the CAM, the TJE and EGF were treated using O-ring. The image was taken 7 days after the treatment with the TJE and EGF. (B) RNA extracted from Chick's organ was quantitatively analyzed by qPCR using human-specific gene primer. Compared to control; ${ }^{\mathrm{P}} \mathrm{P}<0.05,{ }^{* * *} \mathrm{P}<0.001$ and compared to EGF-stimulated group; ${ }^{*} \mathrm{P}<0.05$, ${ }^{\# \#} \mathrm{P}<0.001$ (each experiment $\mathrm{n}=3$ ). N.S., not significant.

using Chick's organ tissue, the EGF treatment group cancer cells were detected with human-specific genes especially the brain and heart tissue. Despite the EGF stimulation in cellular matrix, TJE co-treatment group had reduced detection of human-specific genes and it is not detected similarly to that in normal Chick's organ tissue.

\section{Discussion}

The number of patients who die from lung cancer is steadily increasing worldwide. Previous studies have shown that smoking is the leading cause of lung cancer, and smoking cessation has become active worldwide (1-3). However, recent research found that lung cancer incidence can not be suppressed simply by quitting, and they found that another reason for lung cancer is outdoor pollution. It was found that many factors in the air induce over-activation of surface proteins such as growth factor receptors, and induce cancerization (4-6). In particularly, the over-activation of EGFR has been shown to induce abnormal proliferation and metastasis to normal organ resulting in the death of the patient. Thus, finding a substance that can inhibit the EGFR activation has become a very important research topic. In this study, we investigated the mechanism of inhibiting the cancer cell abnormal metastasis by EGFR inactivation through the TJE treatment. First of all, we examined the inhibitory effect of the TJE in the abnormal metastasis of cancer cells. We confirmed that the number of the metastatic cells was reduced concentration-dependently. In addition, the range of the wound healing area and metastasis-related protein expression were not different in the TJE treatment group when compared with the normal condition (Fig. 1). The activity of EGFR and its downstream proteins was also reduced when compared with the EGF-stimulated group (Fig. 2A).

Recent studies have shown that dimer formation of EGFR and Stat3 play a crucial role in nucleus translocation (18-20). We showed that the formation of dimer by EGF-stimulation was inhibited by the TJE treatment. We 
confirmed that the intranuclear translocation of EGFR and the co-binding with Stat 3 were inhibited by TJE treatment in EGF-stimulated A549 lung cancer cells (Fig. 2C and D). We examined the expression of cancer cell abnormal metastasis and metastasis-related factor compared with EGFR, Stat3 and JAK2 knockdown group using a siRNA transfection. The cancer cell metastasis and expression of related factors was decreased in EGFR knockdown group and TJE treated group when compared with EGF-stimulated group (Fig. 3). Moreover, we confirm that the formation of stress fiber, which is a cell metastasis marker, decreased. However, in the knockdown group of Stat3, the inhibition of cancer metastasis and the expression of related factors did not appear. This indicates that EGFR can induce cancer metastasis without going through Stat3. Previous studies have found that the activity of EGFR can induce cancer cell metastasis and proliferation through its own dimer formation without co-binding with Stat3 $(18,21,22)$. Base on the above results, it was confirmed that the TJE that we secured not only regulates the EGFR signaling pathway but inhibits the cancer cell metastasis due to the EGFR-exclusive activity. In addition, the inhibitory effect of the TJE on cancer cell metastasis was confirmed by CAM assay. As a result, it was confirmed that human cancer cells were invasive to CAM organs in the EGF-stimulated group, whereas it did not appear in the TJE treated group even by EGF-stimulation (Fig. 4).

In conclusion, we suggest that the inhibitory effect of the TJE major fraction substance in the cancer abnormal metastasis is indicated by regulation of EGFR signaling pathway and suppression of its own activity through the targeting of EGFR. Therefore, we demonstrated that TJE has potential as an anticancer metastasis agent and may provide a substitute for chemotherapeutic drugs.

\section{References}

1. Ferlay J, Soerjomataram I, Dikshit R, Eser S, Mathers C, Rebelo M, Parkin DM, Forman D and Bray F: Cancer incidence and mortality worldwide: Sources, methods and major patterns in GLOBOCAN 2012. Int J Cancer 136: E359-E386, 2015.

2. Mathers CD, Fat DM, Inoue M, Rao $C$ and Lopez AD: Counting the dead and what they died from: An assessment of the global status of cause of death data. Bull World Health Organ 83: 171-177, 2005.

3. Torre LA, Bray F, Siegel RL, Ferlay J, Lortet-Tieulent J and Jemal A: Global Cancer Statistics. CA Cancer J Clin 65: 87-108, 2015.

4. Hamra GB, Guha N, Cohen A, Laden F, Raaschou-Nielsen O, Samet JM, Vineis P, Forastiere F, Saldiva P, Yorifuji T, et al: Outdoor particulate matter exposure and lung cancer: A systematic review and meta-analysis. Environ Health Perspect 122: 906-911, 2014.

5. Straif K, Cohen A and Samet J (eds): Air Pollution and Cancer. IARC Scientific Publication No. 161. IARC Press, Lyon. https://www.iarc.fr/en/publications/books/sp161/ AirPollutionandCancer161.pdf.
6. International Agency for Research on Cancer: Personal Habits and Indoor Combustions. IARC Monographs on the Evaluation of Carcinogenic Risks to Humans. Vol. 100E. IARC Press, Lyon. http://monographs.iarc.fr/ENG/Monographs/vol100E/ mono100E.pdf.

7. Líbalová H, Krčková S, Uhlíŕová K, Kléma J, Ciganek M, Rössner P Jr, Srám RJ, Vondráček J, Machala M and Topinka J: Analysis of gene expression changes in A549 cells induced by organic compounds from respirable air particles. Mutat Res 770: 94-105, 2014.

8. Krishnan VG, Ebert PJ, Ting JC, Lim E, Wong SS, Teo AS, Yue YG, Chua HH, Ma X, Loh GS, et al: Whole-genome sequencing of Asian lung cancers: Second-hand smoke unlikely to be responsible for higher incidence of lung cancer among Asian never-smokers. Cancer Res 74: 6071-6081, 2014.

9. Alper O, Bergmann-Leitner ES, Bennett TA, Hacker NF, Stromberg K and Stetler-Stevenson WG: Epidermal growth factor receptor signaling and the invasive phenotype of ovarian carcinoma cells. J Natl Cancer Inst 93: 1375-1384, 2001.

10. Ahmed N, Maines-Bandiera S, Quinn MA, Unger WG, Dedhar S and Auersperg N: Molecular pathways regulating EGF-induced epithelio-mesenchymal transition in human ovarian surface epithelium. Am J Physiol Cell Physiol 290: C1532-C1542, 2006.

11. Siegelin MD and Borczuk AC: Epidermal growth factor receptor mutations in lung adenocarcinoma. Lab Invest 94: 129-137, 2014.

12. Yeom SY,Nam DH and Park C: RRAD promotes EGFR-mediated STAT3 activation and induces temozolomide resistance of malignant glioblastoma. Mol Cancer Ther 13: 3049-3061, 2014.

13. Hipp S, Walch A, Schuster T, Losko S, Laux H, Bolton T, Höfler $\mathrm{H}$ and Becker KF: Activation of epidermal growth factor receptor results in snail protein but not mRNA overexpression in endometrial cancer. J Cell Mol Med 13: 3858-3867, 2009.

14. Anupama EG, Oliver B and Khatri L: Nuclear signaling of EGFR and EGFRvIII in glioblastoma. In: Molecular Targets of CNS tumors. Garami M (ed). InTech, Rijeka, Croatia, 2011. https:// www.scribd.com/document/112167777/Molecular-Targets-ofCNS-Tumors.

15. Gong $\mathrm{C}$, Zhang $\mathrm{Y}$, Shankaran $\mathrm{H}$ and Resat $\mathrm{H}$ : Integrated analysis reveals that STAT3 is central to the crosstalk between HER/ ErbB receptor signaling pathways in human mammary epithelial cells. Mol Biosyst 11: 146-158, 2015.

16. Lo HW, Hsu SC, Ali-Seyed M, Gunduz M, Xia W, Wei Y, Bartholomeusz G, Shih JY and Hung MC: Nuclear interaction of EGFR and STAT3 in the activation of the iNOS/NO pathway. Cancer Cell 7: 575-589, 2005.

17. Kim GT, Lee SH and Kim YM: Torilis japonica extract, a new potential EMT suppressor agent by regulation of EGFR signaling pathways. Int J Oncol 45: 1673-1679, 2014.

18. Brand TM, Iida M, Luthar N, Starr MM, Huppert EJ and Wheeler DL: Nuclear EGFR as a molecular target in cancer. Radiother Oncol 108: 370-377, 2013.

19. Liu L, McBride KM and Reich NC: STAT3 nuclear import is independent of tyrosine phosphorylation and mediated by importin-alpha3. Proc Natl Acad Sci USA 102: 8150-8155, 2005.

20. Michael V, Tamas D, Dzina K, Swen L, Anne S, Valeria P, Walter $\mathrm{R}$ and Gerhard MN: The role of the N-terminal domain in dimerization and nucleocytoplasmic shutting of latent STAT3. J Cell Sci 124: 900-909, 2010.

21. Wang SC and Hung MC: Nuclear translocation of the epidermal growth factor receptor family membrane tyrosine kinase receptors. Clin Cancer Res 15: 6484-6489, 2009.

22. Lo HW, Hsu SC and Hung MC: EGFR signaling pathway in breast cancers: From traditional signal transduction to direct nuclear translocalization. Breast Cancer Res Treat 95: 211-218, 2006. 